\title{
Heat Transfer Augmentation of Concentrated Solar Absorber Using Modified Surface Contour
}

\author{
Ramalingam Senthil ${ }^{*}$, Arvind Chezian, Zackir Hussain Ajmal Arsath \\ Department of Mechanical Engineering, SRM Institute of Science and Technology, Kattankulathur, Chennai, India \\ Received 09 May 2020; received in revised form 27 July 2020; accepted 19 October 2020 \\ DOI: https://doi.org/10.46604/ijeti.2021.5676
}

\begin{abstract}
This work aims to compare the cavity surface contour's thermal performance to that of the solar absorber's plain surface contour for Scheffler type parabolic dish collectors. The absorber is tested for the temperature range up to $600^{\circ} \mathrm{C}$ without working fluid and $180^{\circ} \mathrm{C}$ with the working fluid. The modified absorber surface's thermal performance is compared with the flat surface absorber with and without heat transfer fluid. The peak temperature reached by the surface modified absorber $\left(534^{\circ} \mathrm{C}\right)$ is about $8.6 \%$ more than that of the unmodified absorber $\left(492^{\circ} \mathrm{C}\right)$ during an outdoor test without fluid. The energy efficiency of cavity surface absorber and plain surface absorber are $67.65 \%$ and $61.84 \%$, respectively. The contoured cavity surface produces a more uniform temperature distribution and a higher heat absorption rate than the plain surface. The results are beneficial to the design of high-temperature solar absorbers for concentrated solar collectors.
\end{abstract}

Keywords: parabolic dish, solar absorber, surface cavity, energy efficiency, exergy efficiency

\section{Introduction}

Energy security is the main driving force for a country's sustainable development. The parabolic dish collectors are working at a higher concentration ratio and produce steam for several thermal applications. The Scheffler type parabolic dish collectors are working with a fixed-focus solar absorber and a tracking dish reflector. Sakhaei and Valipour [1] reviewed the effect of design parameters and various heat transfer enhancement methods of flat plate solar collectors. The heat transfer fluid (HTF) flow path modification is also an important aspect of the absorber to improve solar collectors' thermal performance.

Energy and exergy analysis of a corrugated absorber plate-based solar collector using water and air as HTF was investigated by Pathak et al. [2]. Lakshmipathy and Sivaraman [3] investigated the effect of the length-to-diameter ratio of flat plate cavity collectors in parallel flow mode, and the optimized value of 78.74 was determined at the HTF flow rate of 0.002 $\mathrm{kg} / \mathrm{s}$. Jilte et al. [4] investigated different absorber cavity shapes for parabolic dish collectors (PDC). The lowest and highest convective heat loss was with the conical cavity and the spherical cavity, respectively.

Assari et al. [5] proved a solar collector with the triangular HTF passages with a higher efficiency among the rectangular and circular paths. Steel absorbers are preferably used in concentrated solar collectors due to the strength at high-temperature and cost-effectiveness [6-7]. The nonuniform temperature distribution was one of the factors seen in the point-focus solar absorbers, and the effect was minimized using modified HTF flow path and phase change materials in the solar absorbers [8-9]. Abuşka [10] observed higher thermal efficiency of the solar air heater (SAH) with a conical surface structure for all operating conditions.

* Corresponding author. E-mail address: senthilr@ srmist.edu.in 
Khalil et al. [11] studied the different arrangements of turbulators in SAH and showed the highest exergy efficiency for inclined staggered turbulators. Das et al. [12] were compared the plain absorber with a sand coated absorbing surface of a SAH. The sand coated absorber plate's thermal efficiency was enhanced by up to $17 \%$ than that of the plain absorber plate due to increased surface area. Furthermore, the solar collector's thermal efficiency varied from $19 \%$ to $41 \%$ under the different operating conditions. Jain et al. [13] discussed the importance of V-shaped artificial roughness to enhance SAH's heat transfer.

Jouybari and Lundström [14] investigated a thin and porous medium layer on the absorber plate of SAH, and the friction factor was found to be increased twice. The heat transfer was improved due to the enhanced turbulent flow over the porous absorber layer. Hussain and Lee [15] showed a double-layer concentric absorber as an effective technique for uniform heat flow in a novel conical solar collector. Abuseada and Ozalp [16] investigated the effect of the solar receiver's aperture size on concentrated collectors. A smaller aperture size reduced the non-uniformity of temperature.

Cherif et al. [17] preferred the choice of low height of solar absorbers for a PDC. Such receivers were found effective in reducing heat losses from the high-temperature solar receiver. The impact of phase change material (PCM) container's horizontal and vertical orientation in the concentrated solar absorber is determined and the vertical arrangement is found to be effective [18]. A conical cavity solar receiver for PDC was showed to have effective heat absorption for process heating [19].

Xiao et al. [20] determined that the effective mass flow rate for a cylindrical cavity receiver in a PDC is $0.02 \mathrm{~kg} / \mathrm{s}$. PCM integrated solar receivers have been investigated recently by several researchers to maintain uniform heat distribution inside the receiver [21-23]. The use of triangular-shaped bodies in SAH was found to be active in enhancing the collector efficiency [24]. The different absorber configurations of SAH are reviewed, and more turbulence creators produced higher thermal performance [25].

Several studies are carried out from the literature on the use of artificial friction and turbulence creators towards significant heat transfer augmentation at the SAH absorber. Some researches have been investigated on the designs of solar absorbers for PDC. The limited literature on the absorber surface contour modification of the concentrated solar absorbers involves liquid medium as HTF. The nonuniform temperature distribution and heat losses are important concerns of the high-temperature solar absorbers.

Cavity absorbers were observed to be useful devices to absorb heat due to the increase in surface area. However, the weight and cost of such absorbers are limiting commercial deployments. Hence, this investigation is trying to use the benefits of cavity aspects on the flat surface solar absorbers to reduce the material bulkiness, complexity, and cost towards commercial deployments. Two surface contours of cylindrical volumetric type solar absorber are made as plain and cylindrical cavity. Two solar absorbers of plain surface and cavity surface are tested in real-time with the PDC to compare the thermal performance.

\section{Material and Method}

Two solar absorber surface contours are investigated with a PDC with the reflector area of $16 \mathrm{~m}^{2}$. The absorber diameter is $406 \mathrm{~mm}$ with a width of $100 \mathrm{~mm}$. The absorber incident surface is made up of a $15 \mathrm{~mm}$ thick mild steel plate, and all other sides are $5 \mathrm{~mm}$ thick. Both absorber contours are shown in Fig. 1. This absorbing surface is modified with 37 numbers of cylindrical cavities of each with $30 \mathrm{~mm}$ diameter and $10 \mathrm{~mm}$ depth. The end of the cylindrical cavity is a conical shape to act as the cylinder-cone combination effects by allowing more internal reflections and effective heat absorption.

There are six $1.5 \mathrm{~mm}$ thick steel fins fixed inside in such a way to make the flow of water. Water enters the absorber's periphery through two inlets and leaves the absorber from the top outlet. The flow of water from the periphery involves a serpentine path through the attached metal fins in a vertical direction. HTF is mixed in the middle of the absorber and leaves the solar absorber. The volumetric capacity of the absorber is 10 liters. A Scheffler type PDC made up of hardened steel in an oval frame with solar grade mirrors (reflectivity, 0.9) is used to test the solar absorber, as shown in Fig. 2. 


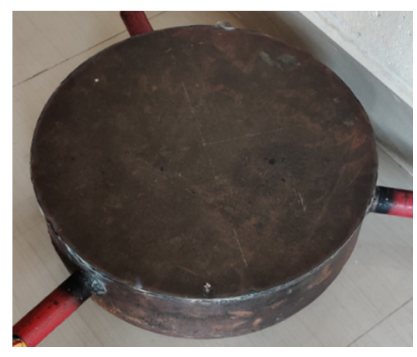

(a) The absorber with plain surface

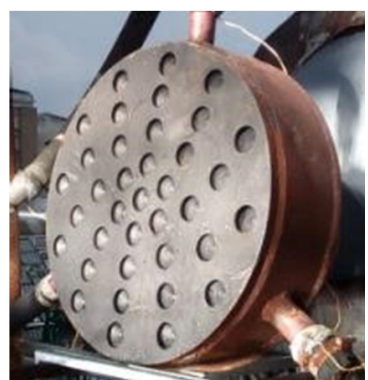

(b) The absorber with modified cavity surface

Fig. 1 Two contoured (plain and cavity) surface absorbers without black coating

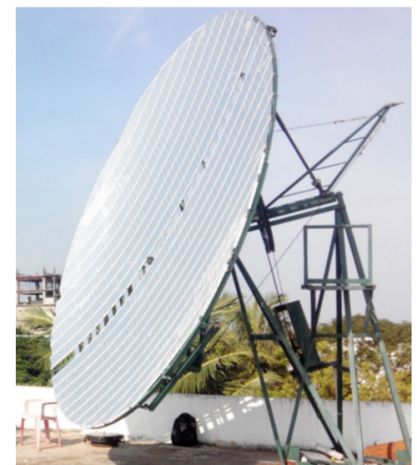

(a) The parabolic dish collector

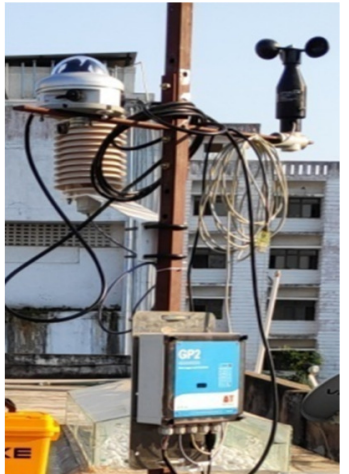

(b) The weather station at the test site

Fig. 2 PDC experimental setup

The schematic layout of the PDC experimental setup is shown in Fig. 3. The focal distance of the solar absorber is fixed at $2.75 \mathrm{~m}$ from the center of the dish. Two-way axis tracking is applied to PDC to keep the focus on the solar absorber. A pump is used to supply water to the solar receiver from the supply tank (120 liters capacity).

The experimental test is conducted as per the test standards of ASHRAE [26]. The testing involves a single phase of fluid to compare both the surface contours. The outdoor testing has been carried out on non-cloudy and sunny days in March 2020. The resistance type detector sensors-based thermocouple is used to measure the absorbers and fluid temperatures. All the temperature data are recorded by using a data logging system (34970A, Agilent Technologies).

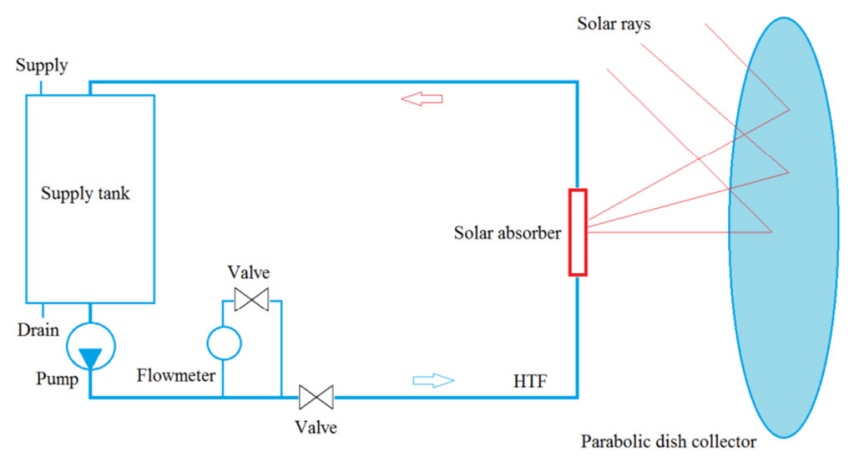

Fig. 3 The schematic layout of PDC experimental setup with solar cavity absorber

\section{Performance Calculation}

Thermal performance calculations for the solar absorber are determined based on the experimental measurements and the operating parameters at the test site. The useful heat gain by $\operatorname{HTF}\left(Q_{u}\right)$ is determined by:

$$
Q_{u}=m C_{p}\left(T_{0}-T_{i}\right)
$$

where $\mathrm{C}_{\mathrm{p}}$ is the liquid specific heat, $\dot{m}$-is the mass flow rate, $\mathrm{T}_{\mathrm{i}}$ and $\mathrm{T}_{\mathrm{o}}$ are inlet and outlet temperature of HTF, respectively. 
The heat loss from the receiver surface is determined by:

$$
Q_{l}=h A_{r}\left(T_{w}-T_{a}\right)+\sigma A_{r} \varepsilon\left(T_{w}^{4}-T_{a}^{4}\right)
$$

where $h$ combines natural and forced convection heat transfer coefficient, $A_{r}$ is the surface area of the receiver, $T_{s}$ is the average receiver surface temperature, $\sigma$ is Stefan-Boltzmann constant, $\varepsilon$ is the emissivity of receiver surface, and $T_{a}$ is the ambient temperature.

Energy efficiency $(\eta)$ is calculated from the HTF temperatures and the incident solar radiation, which can be obtained by:

$$
\eta=\frac{Q_{u}}{A_{c} \eta_{\text {optical }} I_{b}}
$$

where $I_{b}$ solar irradiance, $A_{c}$ is the reflector aperture area, and $\eta_{\text {optical }}$ is the optical efficiency $(=76 \%)$. The optical efficiency of the collector is determined by the product of the mirror reflectivity $(0.91)$ and absorptivity of the surface $(0.85)$.

Exergy efficiency is calculated as per the Eq. (4) based on [27-28],

$$
\eta_{e x}=\frac{m\left(C_{p}\left(T_{0}-T_{i}\right)-T_{a} C_{p} \ln \frac{T_{0}}{T_{i}}\right.}{I_{b} A_{c}\left(1-\frac{4 T_{a}}{3 T_{\text {sun }}}+\left(\frac{T_{a}}{T_{\text {Sun }}}\right)^{4}\right)}
$$

where $T_{\text {Sun }}$ is the temperature of $\operatorname{Sun}\left(5600^{\circ} \mathrm{C}\right)$, and $A_{c}$ is the aperture area of the reflector.

\section{Measurement and Uncertainty}

A weather station (AT Delta-T Make, WS-GP2 Model) is chosen for this study, which includes sensors for measuring solar radiation, wind speed, wind direction, relative humidity, and air temperature. All the measurements are recorded by using the inbuilt Delta Link data logger. Agilent data logger (34970A) is used to record the temperatures of the absorber plate and water. Infra-red thermometer is used to measure the temperature at the solar absorber surface's spatial locations to determine the average surface temperature. Table 1 shows the measurement uncertainties. An uncertainty analysis is done to validate the experimental results [29-30]. The uncertainties of energy and exergy efficiencies of the receiver are calculated by:

$$
\Delta Y=\sqrt{\sum\left(\frac{\delta Y}{\delta X_{i}} \Delta X_{i}\right)^{2}}
$$

where $\Delta Y$ is the overall uncertainty of experiment, $X_{i}$ is the measured quantity, $\delta X_{i}$ and $\delta Y$ are the uncertainties in the measured and derived quantities respectively.

Table 1 Uncertainty analysis

\begin{tabular}{|c|c|c|c|}
\hline Parameter & Range & Percentage of error (\%) & Uncertainty \\
\hline Solar radiation intensity & $0-4000 \mathrm{~W} / \mathrm{m}^{2}$ & $\pm 3.5 \%$ & $\pm 20 \mathrm{~W} / \mathrm{m}^{2}$ \\
\hline Mass flow rate & $0-300 \mathrm{~kg} / \mathrm{h}$ & $\pm 2 \%$ & $\pm 0.05 \mathrm{~kg} / \mathrm{s}$ \\
\hline Wind speed & $0-25 \mathrm{~m} / \mathrm{s}$ & $\pm 0.5 \%$ & $\pm 0.01 \mathrm{~m} / \mathrm{s}$ \\
\hline Temperature & $0-300^{\circ} \mathrm{C}$ & $\pm 1 \%$ & $\pm 0.01^{\circ} \mathrm{C}$ \\
\hline
\end{tabular}

The uncertainty in the energy and exergy performances is determined as $\pm 4.7 \%$ and $\pm 5.2 \%$, respectively, for the HTF flow rate of $90 \mathrm{~kg} / \mathrm{h}$. The newly constructed solar absorber with cylindrical surface contour is tested on sunny days. The tests are conducted to heat 120 liters of water from ambient conditions to the boiling point as test standards of solar thermal collectors. 
The thermal performance improvement of the cavity surface contour solar absorber is compared to that of the plain surface contour reported in the following section.

\section{Results and Discussion}

The experimental study of solar absorber with plain and cavity surface contours is discussed in this section. HTF is considered in the liquid state as per the ASHRAE test standards. The outdoor testing is carried out around noon for receiving high solar radiation in March 2020. The test site is in Chennai, India (Latitude \& Longitude: $12.82^{\circ} \mathrm{N}, 80.04^{\circ} \mathrm{E}$ ). The solar beam radiation is observed between 600 and $800 \mathrm{~W} / \mathrm{m}^{2}$. The wind speed $(0-2.4 \mathrm{~m} / \mathrm{s})$ and the ambient temperature $\left(32-36^{\circ} \mathrm{C}\right)$ are measured at the site. The stagnation test without HTF and actual test with HTF have been conducted, and the noteworthy results are discussed in this section.

\subsection{Stagnation test}

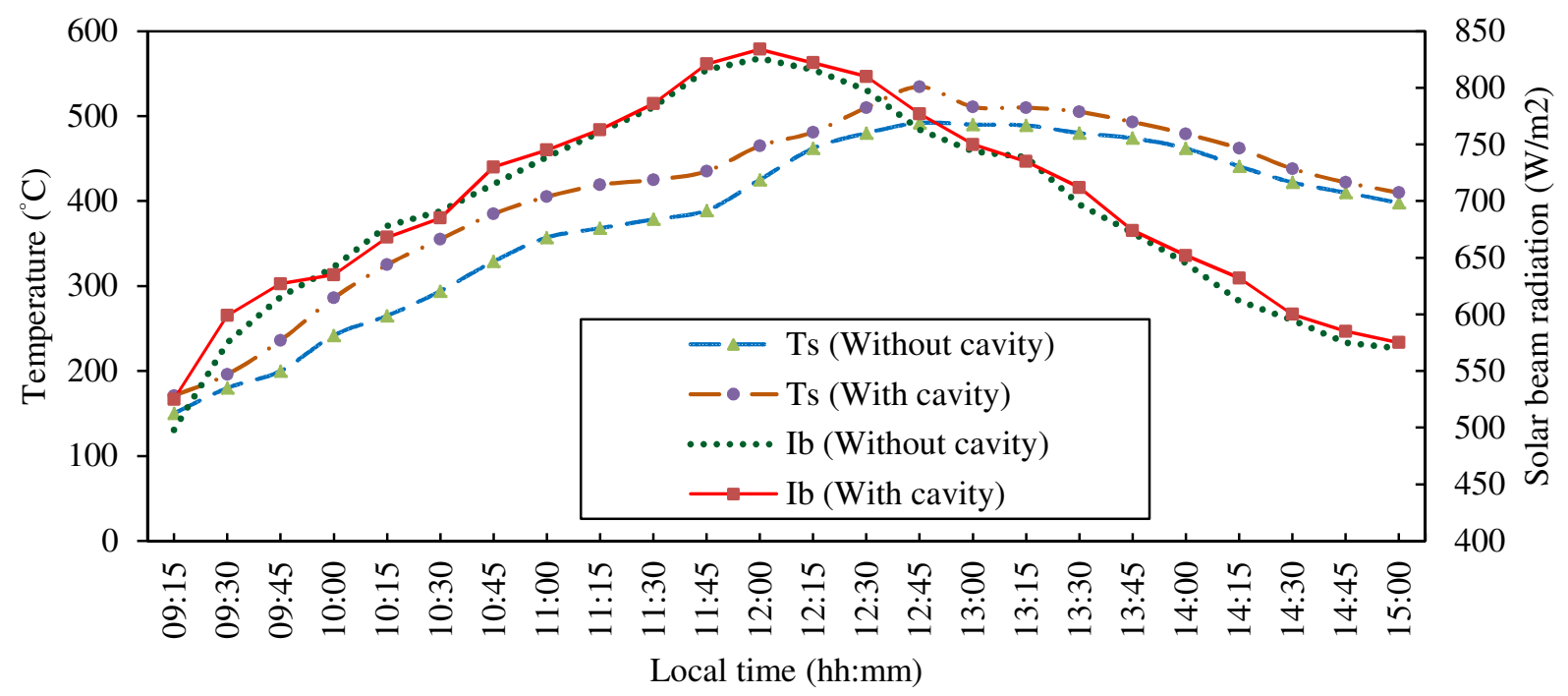

Fig. 4 The variations of average surface temperature of plain and cavity type solar absorbers over the test duration (The one without cavity is tested on $2^{\text {nd }}$ March 2020; The one with cavity is tested on $3^{\text {rd }}$ March 2020)

The stagnation test of the plain and cavity surface is carried out outdoor without passing HTF through the absorber. The temperature of the solar receiver is measured by using the thermocouples which are fixed inside the absorber. Three trials are carried out on each absorber, and the nearly matching input solar radiation trials are chosen to compare the thermal behavior of both absorbers. The outdoor testing is done with the PDC from 9:00 a.m. to 3:00 p.m. on bright sunny days in March 2020. The average beam solar radiation for the plain and cavity surface is observed to be around $690 \mathrm{~W} / \mathrm{m}^{2}$ and $697 \mathrm{~W} / \mathrm{m}^{2}$, respectively.

The average temperature of the contoured cavity absorber is observed about $32^{\circ} \mathrm{C}$ higher than that of the absorber with a plain surface. Furthermore, the average stagnation temperature varies between $380^{\circ} \mathrm{C}$ and $530^{\circ} \mathrm{C}$ because there is no $\mathrm{HTFs}$, and the absorber heat losses by convection and radiation are dominated at such higher temperatures. The contoured cavity absorber shows about $8.6 \%$ higher temperature from the stagnation tests than that of the plain solar absorber due to the internal reflection of concentrated solar rays inside the cylindrical cavities.

The trend of absorbers surface temperatures of both surface contours over the test duration has been shown in Fig. 4. In the average temperature of absorbers reaching $500^{\circ} \mathrm{C}$, the radiation and convection heat losses are significant beyond $500^{\circ} \mathrm{C}$. The variation between the temperatures of both absorbers is observed to be less. The peak temperature reached by the modified absorber is $534^{\circ} \mathrm{C}$, and the unmodified absorber is $492^{\circ} \mathrm{C}$ during an outdoor test without fluid. The modified surface absorber produces a peak temperature of about $8.6 \%$ higher than that of an unmodified absorber surface. 


\subsection{Energy and exergy analysis}

The water is circulated at the flow rate of $90 \mathrm{~kg} / \mathrm{h}$ through the solar absorber during outdoor testing on both absorbers. The total capacity of water in the tank is 120 liters. The circulation of water is allowed until the water's average temperature in the tank reaches around $100^{\circ} \mathrm{C}$. The HTF flow rate is fixed during the testing of both absorbers. The inlet and outlet temperatures of HTF are observed during the recirculation. Figs. 5 and 6 show the variation of solar beam radiation and HTF temperature during the experimental trials for plain and cavity surface absorber, respectively. The ambient temperature variation is about $5-6^{\circ} \mathrm{C}$ during the trials, and its trend is nearly a horizontal line as per the range of values of the y-axis. Hence, the ambient temperature trend is omitted in the Figures. The tests have been carried out in March 2020.

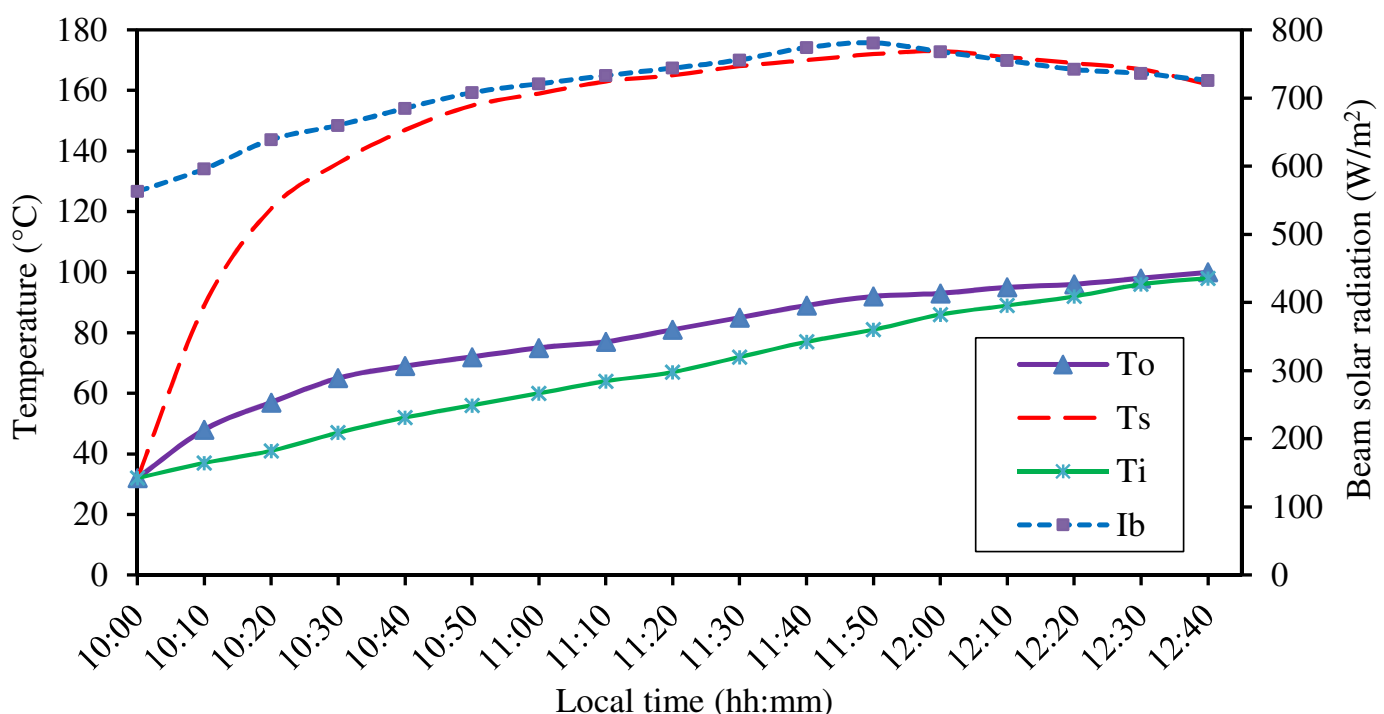

Fig. 5 The variations of average surface temperatures and HTF temperatures of solar absorber with plain surface over the testing period on $5^{\text {th }}$ March 2020

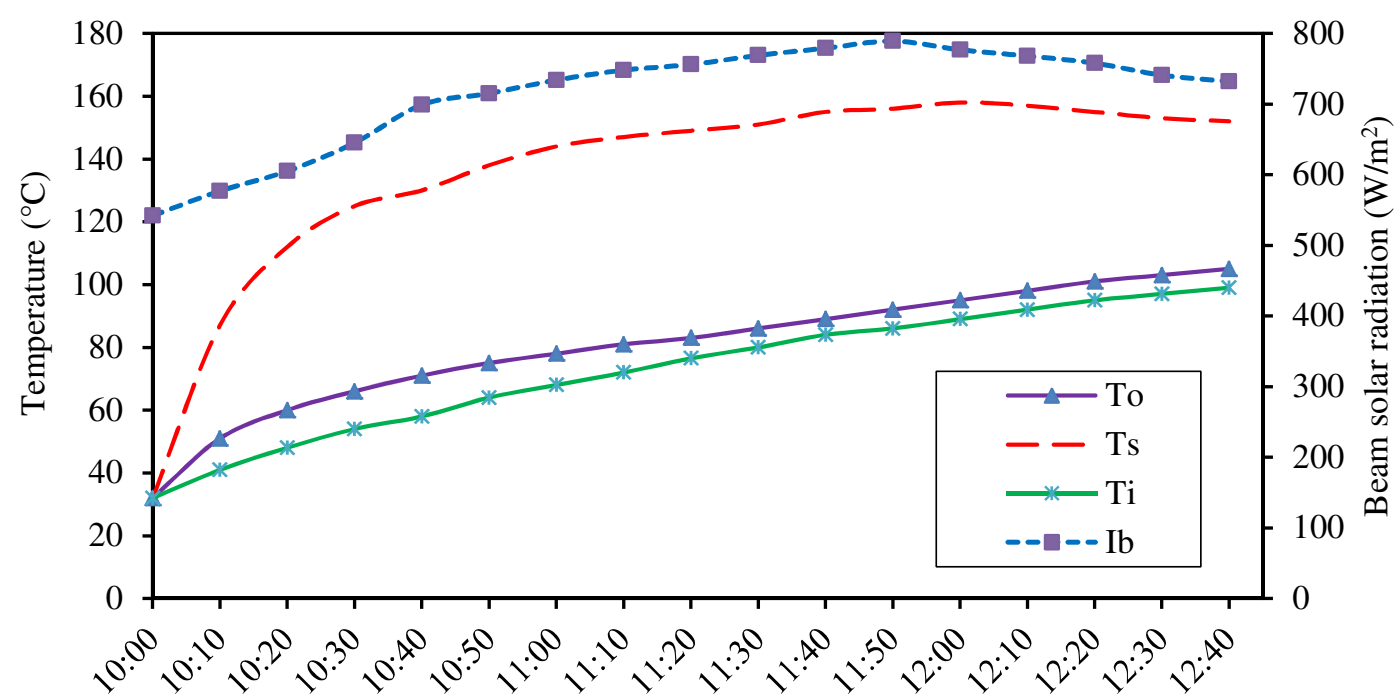

Local time (hh:mm)

Fig. 6 The variations of average surface temperature and HTF temperatures of solar absorber with cavity surface over the testing period on $7^{\text {th }}$ March 2020

During the tests, the average beam solar radiation is measured to be about 711 and $715 \mathrm{~W} / \mathrm{m}^{2}$ for the plain and cavity absorbers, respectively. Wind speed is considered for the convection heat losses from the absorber surface. The average absorber surface temperature lies in the range of $140-150^{\circ} \mathrm{C}$. The lower absorber surface temperature is observed for cavity absorber due to the higher convection heat transfer inside the absorber, and the incident heat flux is uniformly distributed in the absorber. 
Because of the low surface temperature of the cavity absorber, the radiative and convective heat loss is more moderate. The total heat loss from the cavity surface absorber is about $8 \mathrm{MJ}$, whereas about 9.4 MJ for the plan surface contour absorber. Even though the absorber and materials' volume are the same between both the absorbers, the absorber surface area of the cavity surface contour has been increased about $27.84 \%$ more than that of the plain absorber aperture area. The increased surface area is responsible for distributing the incident heat flux uniformly.

The absorber's weight with a plain surface is about $15.343 \mathrm{~kg}$, and the weight of contoured cavity absorber is $13.136 \mathrm{~kg}$. Due to the materials removed to form the cylindrical contoured cavities on the absorber plate, the absorber is $2.207 \mathrm{~kg}$ less than the plain surface absorber. The black coating is common for both absorbers (absorptivity of 0.85). Hence, the optical efficiency of the solar collector is about 0.77 .

Fig. 7 summarizes the experimental trials' thermal performance conducted on the plain and the modified solar absorbers for PDC. The exergy performance of the modified surface contour is observed to be improved significantly. Similar solar input conditions are considered during the analysis. The variation of ambient temperature is also observed to be a smaller value. The overall heat loss coefficient of plain and cavity surface is compared, as shown in Fig. 8. The average heat loss coefficient of the cavity surface is about $30 \%$ lesser than that of the plain surface due to convection and radiation effects.

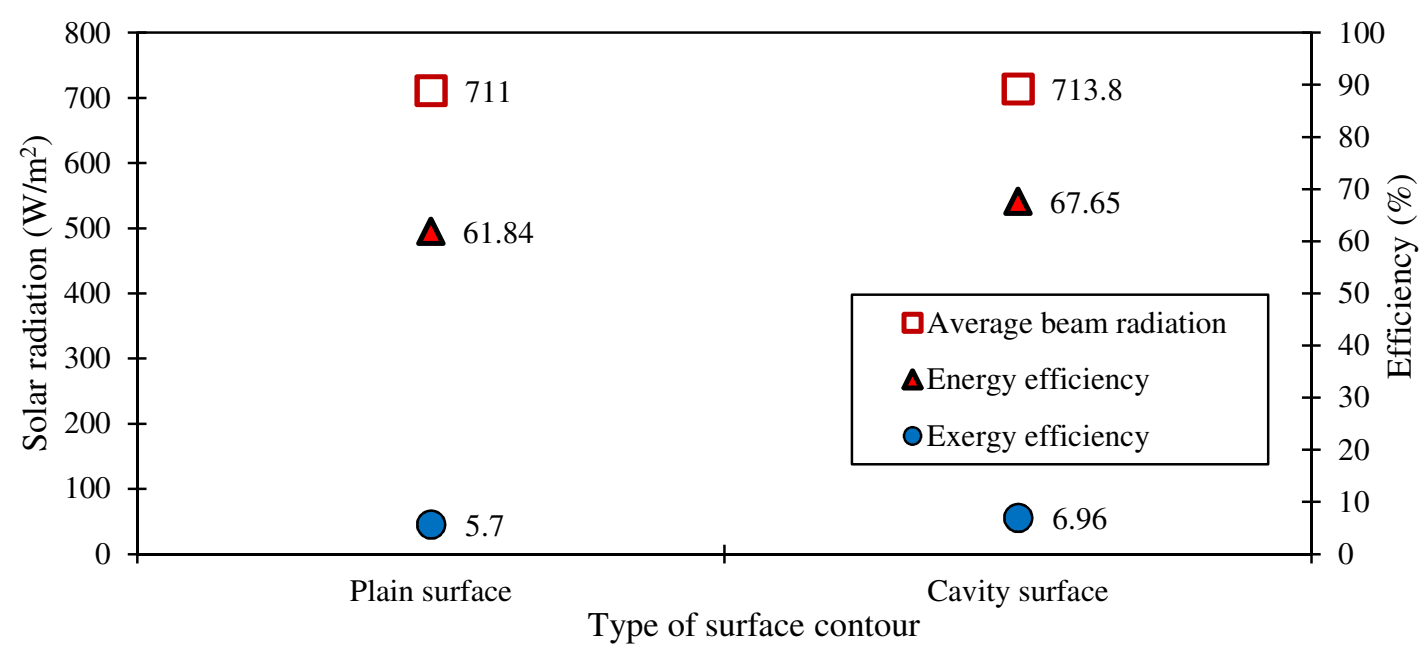

Fig. 7 The variations of thermal performance of the solar absorbers with and without cavity surface

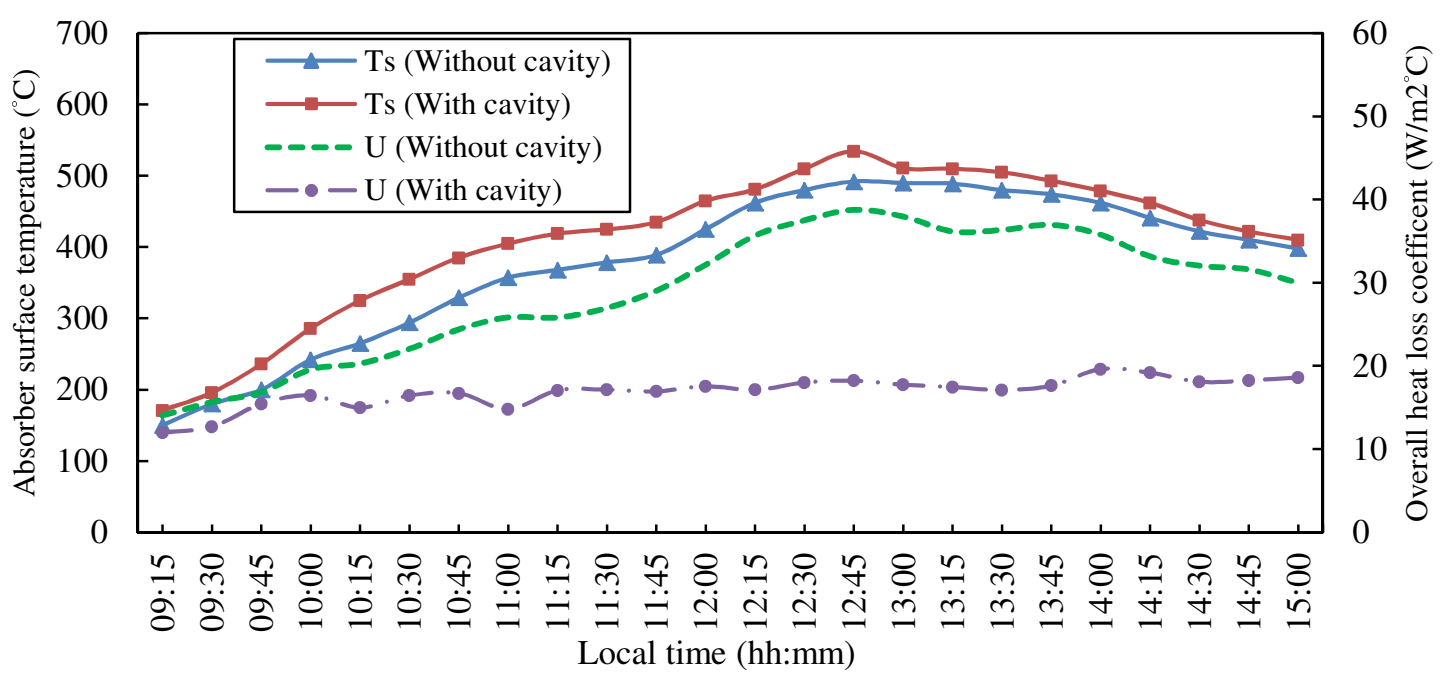

Fig. 8 The variation of overall heat loss coefficient of the plain and cavity surface solar absorbers about similar operating conditions

The average energy and exergy analysis of both absorbers are determined based on the solar radiation input and HTF temperatures. The energy efficiency of the cavity and plan surface absorber is determined about $67.65 \%$ and $61.84 \%$, respectively. The plain and cavity surface absorber's exergy efficiency is calculated as $5.7 \%$ and $6.98 \%$, respectively. At the 
outdoor test conditions, the energy and exergy efficiency improvement in the modified contoured cavity of the solar absorber surface is observed to be around $9 \%$ and $22 \%$, respectively. Thus, the contoured cavity is beneficial to improve the solar absorbers' exergy performance for PDC.

Table 2 shows the comparaison of energy efficiency of the present cavity surface solar absorber with similar studies and Scheffler type PDC. However, the design of the different shapes of contoured surface is studied for the optimum optical performance. A circulating pump is used to circulate the water from the tank to the absorber, and the tank is natually aspirated and maintained at atmospheric pressure. The operating parameters such as HTF flow rate and the correspoding pressure drop caused by the protruded absorber surface with the pumping power have to be quantified to improve the concentrated solar absorbers' thermal performance.

Table 2 Results with previously published works on Scheffler type PDC

\begin{tabular}{|c|c|}
\hline Major findings & Reference \\
\hline $\begin{array}{c}\text { The energy efficiency of PCM based solar receiver is of about } 64.4 \% \text { at } \\
\text { average solar radiation of about } 640 \mathrm{~W} / \mathrm{m}^{2}\end{array}$ & {$[21]$} \\
\hline Conical cavity solar absorber produced energy efficiency about $57.4 \%$ & {$[19]$} \\
\hline An average energy efficiency of a cylindrical cavity is about $67.5 \%$ & {$[20]$} \\
\hline $\begin{array}{c}\text { The energy efficiency of PCM based solar receiver is about } 66 \% \text { at average } \\
\text { solar radiation of about } 600 \mathrm{~W} / \mathrm{m}^{2}\end{array}$ & {$[9]$} \\
\hline The energy efficiency of the cavity surface contour absorber is about $67.65 \%$ & The present study \\
\hline
\end{tabular}

\section{Conclusions}

The plain and cavity surface contour of the point-focus solar absorber with a Scheffler parabolic dish solar collector were investigated experimentally. The innovative design of solar absorber with several cylindrical cavities on the incident surface formed a more suitable heat exchanger surface because of the increased receiver surface area and uniform temperature distribution compared to the plain-type absorber surface. The thermal performance of the absorbers with the modified surface shape is compared with the flat surface absorber with and without HTF. The major conclusions drawn are given below.

(1) The maximum temperature reached by the absorber surface with a cavity is observed to be about $8.5 \%$ higher than that of the plain absorber surface during outdoor testing without HTF at an average beam solar radiation of $710 \mathrm{~W} / \mathrm{m}^{2}$.

(2) The energy and exergy efficiency of cavity absorber are determined about $67.65 \%$ and $6.98 \%$, respectively. The plain absorber's energy and exergy efficiency are determined about $61.84 \%$, and $5.7 \%$, respectively.

(3) The maximum energy efficiency reached by the absorber surface with a cavity is determined to be about $9.4 \%$ higher than that of the plain absorber surface during outdoor testing with HTF at an average beam solar radiation of $710 \mathrm{~W} / \mathrm{m}^{2}$. The contoured cavity absorber's exergy efficiency is enhanced by $22 \%$ compared to the plain contour absorber surface.

The results indicate that the absorber's modified surface contour is beneficial to absorb maximum incident solar radiation. The contemporary design is determined to be simple, lightweight, and cost-effective compared to the conventional cavity solar absorbers. Thus, the findings help design high-temperature solar receivers with extended feasibility studies on different cavity shapes and optimum HTF flow rates for pumping power.

\section{Nomenclature}

\begin{tabular}{|c|c|}
\hline$A_{c}$ & Aperture area of the PDC $\left(\mathrm{m}^{2}\right)$ \\
\hline$A_{r}$ & Surface area of the solar absorber $\left(\mathrm{m}^{2}\right)$ \\
\hline$C_{p}$ & Specific heat of water $(\mathrm{J} / \mathrm{g}-\mathrm{K})$ \\
\hline$h$ & Wind convective heat transfer coefficient $\left(\mathrm{W} / \mathrm{m}^{2} \mathrm{~K}\right)$ \\
\hline$I_{b}$ & Solar beam radiation $\left(\mathrm{W} / \mathrm{m}^{2}\right)$ \\
\hline$m$ & Mass of flow rate $(\mathrm{kg} / \mathrm{h})$ \\
\hline
\end{tabular}




\begin{tabular}{|c|c|}
\hline$Q_{l}$ & Heat loss (J) \\
\hline$Q_{u}$ & Heat gained by HTF $(\mathrm{J})$ \\
\hline$T_{a}$ & Ambient temperature $(\mathrm{K})$ \\
\hline$T_{i}$ & Inlet temperature of HTF $(\mathrm{K})$ \\
\hline$T_{o}$ & Outlet temperature of HTF $(\mathrm{K})$ \\
\hline$T_{S u n}$ & Sun's surface temperature $(\mathrm{K})$ \\
\hline$T_{w}$ & Receiver wall temperature $(\mathrm{K})$ \\
\hline Abbreviations & \\
\hline HTF & Heat transfer fluid \\
\hline PCM & Phase change material \\
\hline PDC & Parabolic dish collector \\
\hline Greek Symbols \\
\hline$\sigma$ & Stefan-Boltzmann constant $\left(=5.67 \times 10-8 \mathrm{~W} / \mathrm{m}^{2} \mathrm{~K}^{4}\right)$ \\
\hline $\mathcal{E}$ & Emissivity of receiver surface \\
\hline$\eta$ & Energy efficiency $(\%)$ \\
\hline$\eta_{e x}$ & Exergy efficiency $(\%)$ \\
\hline$\eta_{\text {optical }}$ & Optical efficiency (\%) \\
\hline$\Delta Y$ & Overall uncertainty of experiment \\
\hline$X_{i}$ & Measured quantity \\
\hline$\delta X_{i}$ & Uncertainty in the measured quantity \\
\hline$\delta Y$ & Uncertainties in the derived quantity \\
\hline \multicolumn{2}{|c|}{} \\
\hline
\end{tabular}

\section{Acknowledgements}

The authors are grateful to SRM Institute of Science and Technology, Kattankulathur campus, Chennai, India for providing the research facility to carry out the research work.

\section{Conflicts of Interest}

The authors declare no conflict of interest.

\section{References}

[1] S. A. Sakhaei and M. S. Valipour, "Performance Enhancement Analysis of the Flat Plate Collectors: A Comprehensive Review,” Renewable and Sustainable Energy Reviews, vol. 102, pp. 186-204, March 2019.

[2] P. K. Pathak, P. Chandra, and G. Raj, "Comparative Analysis of Modified and Convectional Dual Purpose Solar Collector: Energy and Exergy Analysis,” Energy Sources, Part A: Recovery, Utilization, and Environmental Effects, pp. 1-17, November 2019.

[3] S. Luque, G. Menéndez, M. Roccabruna, J. González-Aguilar, L. Crema, and M. Romero, "Exploiting Volumetric Effects in Novel Additively Manufactured Open Solar Receivers," Solar Energy, vol. 174, pp. 342-351, November 2018.

[4] S. R. Atchuta, S. Sakthivel, and H. C. Barshilia, "Nickel Doped Cobaltite Spinel as a Solar Selective Absorber Coating for Efficient Photothermal Conversion with a Low Thermal Radiative Loss at High Operating Temperatures," Solar Energy Materials and Solar Cells, vol. 200, article no. 109917, September 2019.

[5] M. R. Assari, H. B. Tabrizi, I. Jafari, and E. Najafpour, "An Energy and Exergy Analysis of Water and Air with Different Passage in a Solar Collector,” Energy Sources Part A: Recovery, Utilization, and Environmental Effects, vol. 36, no. 7, pp. 747-754, February 2014.

[6] B. Lakshmipathy and B. Sivaraman, "Performance Analysis on Working Parameters of a Flat Plate Solar Cavity Collector," International Energy Journal, vol. 16, no. 1, pp. 1-9, March 2016.

[7] R. D. Jilte, S. B. Kedare, and J. K. Nayak, "Natural Convection and Radiation Heat Loss from Open Cavities of Different Shapes and Sizes used with Dish Concentrator," Mechanical Engineering Research, vol. 3, no. 1, pp. 25 , January 2013.

[8] R. Senthil and M. Cheralathan, "Effect of Non-Uniform Temperature Distribution on Surface Absorption Receiver in Parabolic Dish Solar Concentrator,” Thermal Science, vol. 21, no. 5, pp. 2011-2019, 2017.

[9] R. Senthil and M. Cheralathan, "Enhancement of the Thermal Energy Storage Capacity of a Parabolic Dish Concentrated Solar Receiver Using Phase Change Materials," Journal of Energy Storage, vol. 25, article no. 100841, October 2019.

[10] M. Abuşka, "Energy and Exergy Analysis of Solar Air Heater having New Design Absorber Plate with Conical Surface," Applied Thermal Engineering, vol. 131, pp. 115-124, February 2018.

[11] W. H. Khalil, Z. A. H. Obaid, and H. K. Dawood, "Exergy Analysis of Single-Flow Solar Air Collectors with Different 
Configurations of Absorber Plates,” Heat Transfer-Asian Research, vol. 48, no. 8, pp. 3600-3616, August 2019.

[12] B. Das, J. D. Mondol, S. Debnath, M. Smyth, and A. Zacharopoulos, "Effect of the Absorber Surface Roughness on the Performance of a Solar Air Collector: An Experimental Investigation,” Renewable Energy, vol. 152, pp. 567-578, June 2020.

[13] S. K. Jain, G. D. Agrawal, and R. A. Misra, "A Detailed Review on Various V-Shaped Ribs Roughened Solar Air Heater," Heat and Mass Transfer, vol. 55, pp. 3369-3412, June 2019.

[14] N. F. Jouybari and T. S. Lundström, "Performance Improvement of a Solar Air Heater by Covering the Absorber Plate with a Thin Porous Material," Energy, vol. 190, article no.116437, January 2020.

[15] M. I. Hussain and G. H. Lee, "Numerical and Experimental Heat Transfer Analyses of a Novel Concentric Tube Absorber under Non-Uniform Solar Flux Condition,” Renewable Energy, vol. 103, pp. 49-57, April 2017.

[16] M. Abuseada and N. Ozalp, "Experimental and Numerical Study on a Novel Energy Efficient Variable Aperture Mechanism for a Solar Receiver," Solar Energy, vol.197, pp. 396-410, February 2020.

[17] H. Cherif, A. Ghomrassi, J. Sghaier, H. Mhiri, and P. Bournot, "A Receiver Geometrical Details Effect on a Solar Parabolic Dish Collector Performance,” Energy Reports, vol. 5, pp. 882-897, November 2019.

[18] R. Senthil, "Effect of Charging of Phase Change Material in Vertical and Horizontal Rectangular Enclosures in a Concentrated Solar Receiver," Case Studies in Thermal Engineering, vol. 21, article no. 100653, October 2020.

[19] T. Venkatachalam and M. Cheralathan, "Effect of Aspect Ratio on Thermal Performance of Cavity Receiver for Solar Parabolic dish concentrator: An Experimental Study," Renewable Energy, vol. 139, pp. 573-581, August 2019.

[20] L. Xiao, F. W. Guo, S. Y. Wu, and Z. L. Chen, "A Comprehensive Simulation on Optical and Thermal Performance of a Cylindrical Cavity Receiver in a Parabolic Dish Collector System,” Renewable Energy, vol. 145, pp. 878-892, January 2020.

[21] R. Senthil and M. Cheralathan, "Effect of the Phase Change Material in a Solar Receiver on Thermal Performance of Parabolic Dish Collector,” Thermal Science, vol. 21, no. 6 Part B, pp. 2803-2812, 2017.

[22] A. Solé, Q. Falcoz, L. F. Cabeza, and P. Neveu, "Geometry Optimization of a Heat Storage System for Concentrated Solar Power Plants (CSP),” Renewable Energy, vol. 123, pp. 227-235, August 2018.

[23] M. A. Bashir and A. Giovannelli, "Design Optimization of the Phase Change Material Integrated Solar Receiver: A Numerical Parametric Study,” Applied Thermal Engineering, vol. 160, article no. 114008, September 2019.

[24] A. P. Shukla, B. Gupta, R. Kushwaha, and P. K. Jhinge, "Thermal Performance of Solar Air Heater Having Triangular-Shaped Hollow Bodies Inside," Advances in Fluid and Thermal Engineering, Lecture Notes in Mechanical Engineering, pp 147-155, April 2019.

[25] E. Vengadesan and R. Senthil, "A Review on Recent Developments in Thermal Performance Enhancement Methods of Flat Plate Solar Air Collector,” Renewable and Sustainable Energy Reviews, vol. 134, article no. 110315, December 2020.

[26] S. J .B. Hall, Method of Testing to determine the Thermal Performance of Solar Collectors, Atlanta: Ashrae, 1986.

[27] R. Petela, "Exergy of Undiluted Thermal Radiation," Solar Energy, vol. 74, no. 6, pp. 469-488, June 2003.

[28] D. MacPhee and I. Dincer, "Thermal Modeling of a Packed Bed Thermal Energy Storage System during Charging," Applied Thermal Engineering, vol. 29, no. 4, pp. 695-705, March 2009.

[29] S. J. Kine and F. McClintock, "Describing Uncertainties in Single-sample Experiments," Mechanical Engineering, vol. 75, pp. 3-8, January 1953.

[30] R. J. Moffat, "Describing the Uncertainties in Experimental Results," Experimental Thermal and Fluid Science, vol. 1, no. 1, pp. 3-17, January 1988.

Copyright $(\mathrm{C}$ by the authors. Licensee TAETI, Taiwan. This article is an open access article distributed under the terms and conditions of the Creative Commons Attribution (CC BY-NC) license (https://creativecommons.org/licenses/by-nc/4.0/). 